\title{
Effects of volume fraction on water uptake and tensile properties of epoxy filled with inorganic fillers having different reactivity to water
}

\author{
Sugiman Sugiman ${ }^{\mathrm{a}, *}$, Salman Salman ${ }^{\mathrm{a}}$, Maryudi Maryudi ${ }^{\mathrm{b}}$ \\ ${ }^{a}$ Department of Mechanical Engineering, Faculty of Engineering, University of Mataram, Mataram, Nusa Tenggara Barat, Indonesia \\ ${ }^{\mathrm{b}}$ Department of Chemical Engineering, Faculty of Industrial Technology, Universitas Ahmad Dahlan, Yogyakarta, Indonesia
}

\section{A R T I C L E I N F O}

\section{Keywords:}

Inorganic filler

Epoxy

Water reactivity

Water uptake

Swelling

Tensile properties

\begin{abstract}
A B S T R A C T
The paper presents water uptake and tensile properties of epoxy filled with inorganic fillers having different reactivity to water, namely Portland cement, fly ash, and calcium carbonate $\left(\mathrm{CaCO}_{3}\right)$ particles. Portland cement and $\mathrm{CaCO}_{3}$, respectively have the highest and the lowest water reactivity. The filler volume fraction was ranging from 0 to $25 \%$. The results showed that for the reactive filler, with the increase of volume fraction, the water uptake increased and behaved as non-Fickian, whereas for the less reactive filler, the water uptake decreased and behaved as pseudo-Fickian. In dry condition, with the increase of volume fraction, the elastic modulus and tensile strength increased and tended to decrease, respectively, regardless of the filler type. However, in wet condition, the positive effect of filler on the elastic modulus diminished due to excessive plasticization of the matrix, and the reduction of elastic modulus of the most reactive filler is the lowest.
\end{abstract}

\section{Introduction}

Epoxy resin has been increasingly used in engineering structures, such as in aerospace, automobile, marine, and civil engineering as a matrix of advanced composite materials, adhesives, painting and coating [1], and epoxy polymer concrete [2]. However, epoxy is susceptible to absorb water from the surrounding environment, which then can cause a deleterious effect on the physical and mechanical properties of epoxy. The ability of epoxy to absorb water limits its application in the structures, which are often exposed in a moist environment. Therefore, understanding the interaction between water and epoxy system becomes necessary to find a way to reduce water absorption in epoxy and to improve the water-resistance.

Various inorganic fillers have been utilized to increase the waterresistance of epoxy. The fillers could increase the tortuosity path of water diffusion, which can alter the diffusivity and the equilibrium water uptake. However, the influence of filler on those diffusion parameters depends on the shape and size, orientation, the volume fraction of filler, aging temperature and the filler-matrix interaction [3]. A high aspect ratio of nanoparticles is better than microparticles in decreasing the water uptake and diffusivity due to the increase in tortuosity path of water diffusion into the epoxy [4-7]. Water diffused faster when it came from the longitudinal direction of the reinforcement orientation than from the transverse direction of reinforcement orientation, but the equilibrium water uptake was not different significantly [7-9]. The phenomena occurred because, in the longitudinal direction, water can diffuse through both the matrix and the interface of reinforcementmatrix. Similar to the effect of aspect ratio on water diffusion, the increase of filler loading also increased the tortuosity of water diffusion, resulting in a decrease of water uptake and diffusivity $[5,7,10,11]$. However, some fillers do not always show the similar trend with the increase of filler loading. For example, Starkova et al. [12] reported that although adding multi-walled carbon nanotube (MWCNT) decreased the diffusivity of epoxy; however, it did not significantly affect the maximum water uptake. The insignificant effect of MWCNT on the equilibrium water uptake was likely caused by the increase of bonded water due to opening polar groups after introducing MWCNT. Meanwhile, Capiel et al. [13] reported the rise of water uptake with the increase of bentonite content aged at temperature of $22{ }^{\circ} \mathrm{C}$, which was also caused by increasing the polar groups. The aging temperature mainly affected the diffusivity of filled epoxy, where the increase of aging temperature increased the diffusivity, as reported by Liu et al. [7] on the clay-filled epoxy. However, Capiel et al. [13] reported that increasing aging temperature increased both the maximum water uptake and diffusivity on the bentonite-filled epoxy. The increase in water uptake occurred due to the epoxy-anhydride hydrolysis degradation. Chateauminois et al. [14] also reported that increasing aging temperature beyond $50{ }^{\circ} \mathrm{C}$ could promote interfacial degradation in a glass fibre/epoxy composite leading to the increased water uptake for prolonged aging time.

\footnotetext{
* Corresponding author.

E-mail address: s.sugiman@unram.ac.id (S. Sugiman).
} 
Filler-matrix interaction affects water diffusion behavior. Weak interfacial bonding induces micropores in the interface of filler-matrix and becomes pathways for water molecules migration. While the strong interfacial bonding restricted the chain molecules mobility of polymer surrounding the filler particles, and then retarded the polymer molecular relaxation [12]. Nicaise et al. [15] reported that when the adhesion of filler-matrix was strong, there was only one stage of absorption, but there were up to three stages of absorption for the poor adhesion of filler-matrix including: (i) displacement of low adhesion filler at the near saturation, (ii) progressive wetting of debonded particles and (iii) detachment of filler and accumulation of water around the filler. Those stages were more obvious for high content of filler.

Water diffusion is mainly driven by a concentration gradient (Fickian diffusion), but other processes can contribute to the diffusion such as additional cross-link during aging, structural relaxation, hydrolysis, and degradation [16], which results in deviation from Fickian behavior. Various models have been reported to model the anomaly of Fickian diffusion including Langmuir diffusion model [17], dual-stage Fickian diffusion model $[18,19]$, sequentially dual-stage Fickian diffusion [20], diffusion with time-varying diffusivity [21], and diffusionrelaxation model of Berens and Hopfenberg [16]. Langmuir diffusion model considers that the absorbed water can be free and bound water with a probability per unit time $\gamma$ for a free water molecule to be bound and a probability per unit time $\beta$ for a bound water molecule becomes a free water. Gilormini and Verdu [22] evaluated the wide range of $\gamma$ and $\beta$ values and found that at high $\gamma$ value, water was strongly bound to the polar groups and the diffusion behavior was quasi (pseudo)-Fickian.

Besides affecting water absorption behavior, filler introduces waterfiller-epoxy interaction, which then influences the physical and mechanical properties of epoxy. Alamri and Low [5] investigated the addition of nano clay Cloisite 30B, halloysite nanotubes (HNT), and nano silicon carbide ( $\mathrm{SiC}$ ) up to $5 \mathrm{wt} \%$ on the water absorption, the flexural properties and the fracture toughness of epoxy. They found that the water absorption decreased with the increase of filler content, and nano-SiC gave the highest reduction by about $33 \%$ at the filler content of $5 \%$. Furthermore, the addition of those fillers improved the flexural properties and the fracture toughness both in dry and wet conditions compared to the neat epoxy. He et al. [23] reported the water absorption of nano- $\mathrm{CaCO}_{3}$ and its effect on the flexural properties of epoxy composites. They found that by adding $4 \mathrm{wt} \%$ of nano $\mathrm{CaCO}_{3}$, the water uptake reduced by about $36 \%$ compared to that of neat epoxy. In dry condition, the flexural strength increased with the increase of nano $\mathrm{CaCO}_{3}$ content up to $6 \mathrm{wt} \%$, and in wet condition, in general, nano $\mathrm{CaCO}_{3}$ reduced the negative effect of water on the flexural strength. Dittanet et al. [24] used nano- $\mathrm{SiO}_{2}$ at the content of $20 \mathrm{wt} \%$ for filling diglycidyl ether bisphenol-F (DGEBF) and cycloaliphatic-based epoxy and found that the water absorption in both epoxies decreased up to 23 and $32 \%$, respectively. Further, the elastic modulus tended to increase with the nano-silica content linearly, meanwhile, the toughness increased linearly up to the content of $10 \mathrm{wt} \%$, and after that content, it tended to be a plateau. The toughness increases were about 71 and $50 \%$ for DGEBF and cycloaliphatic based epoxy, respectively. Khoramishad and Olizadeh [25] studied a MWCNT up to $0.5 \mathrm{wt} \%$ and nano $\mathrm{SiC}$ up to $5 \mathrm{wt} \%$ to reinforce epoxy and then were exposed in distilled water at a temperature of $60{ }^{\circ} \mathrm{C}$. They reported that by adding $0.1 \mathrm{wt} \%$ of MWCNT and $1 \mathrm{wt} \%$ of $\mathrm{SiC}$, the water uptake decreased by about 26 and $18 \%$, respectively, at the saturation level. Meanwhile, compared to the aged neat epoxy at the saturation level, the tensile strength of filled epoxy was improved by about 32 and $16 \%$ for MWCNT and SiC, respectively.

As the aforementioned studies, the type of filler has different effects on the water absorption, as well as the mechanical properties. Based on the reactivity to water, fillers may be categorized as reactive, semi reactive, and unreactive. Those type of fillers might differently affect water absorption behavior of epoxy. Moreover, the interaction between water and different type of filler further influences the physical and mechanical properties of epoxy. However, to the best author's knowledge, studies on the effect of fillers that have different water reactivity to the water absorption behavior and the mechanical properties of epoxy composites are limited. Previously, authors [26] reported the effect of three types of fillers with different reactivity to water, namely Portland cement, fly ash, and $\mathrm{CaCO}_{3}$ on the water uptake behavior and the tensile and fracture properties in dry and wet conditions. However, the studies were limited only for a certain filler content that has not covered the effect of filler content.

The objective of the paper is to investigate the effect of filler volume fraction on the water absorption behavior, swelling, and tensile properties using the same filler as in Ref. [26]. Infrared spectroscopy was conducted to study the water-filler-epoxy interaction. Scanning electron microscopy was also reported, investigating the morphologies of the tensile fracture surfaces in dry and wet conditions. This work would be helpful in understanding water absorption of filled epoxy with fillers having different reactivity to water in order to improve the water-resistance of epoxy.

\section{Materials and methods}

\subsection{Materials}

Epoxy resin was based on diglycidyl ether bisphenol-A (DGEBA) with hardener of polyaminoamide, obtained from Justus Kimia Raya (Surabaya, Indonesia) with commercial name of Eposchon A and Eposchon B, respectively. The DGEBA has an epoxy equivalent weight of $189 \mathrm{~g} / \mathrm{eq}$, a viscosity of 13,000 MPa.s, and a density of $1.15 \mathrm{~g} / \mathrm{cm}^{3}$. Meanwhile, the polyaminoamide curing agent has an amine hydrogen equivalent weight of $120 \mathrm{~g} / \mathrm{eq}$, a viscosity of 12,000 MPa.s, and a density of $0.97 \mathrm{~g} / \mathrm{cm}^{3}$. The filler used in this study was Portland cement, fly ash, and $\mathrm{CaCO}_{3}$. The Portland cement was purchased from Indocement Tunggal Prakasa Ltd (Cibinong, Indonesia) with an average particle size of $30 \mu \mathrm{m}$. The cement particles were used as received (uncured) and attained the maximum strength after being cured for 28 days, with low hydration heat [27]. This curing time was slightly shorter than the immersion time for mechanical testing (30 days), but about a half of that of the gravimetric study (70 days). Nevertheless, the stability of mechanical properties of cured cement in cement-filled epoxy was less known depending on the water uptake characteristic of filled epoxy. Industrial-grade $\mathrm{CaCO}_{3}$ was commercially purchased, with the average particle size of $15 \mu \mathrm{m}$. Fly ash particle was obtained from Paiton's thermal power plant (East Java, Indonesia). The fly ash particle size was less than $74 \mu \mathrm{m}$, and the particles had been treated using sodium hydroxide (10 wt\%) [28]. Portland cement, fly ash, and $\mathrm{CaCO}_{3}$ were hydrophilic but having different reactivity to water. The highest and the lowest water reactivity filler were respectively Portland cement and $\mathrm{CaCO}_{3}$.

\subsection{Fabrication of the water uptake and tensile specimens}

For manufacturing the specimens, epoxy resin was mixed with fillers (Portland cement, fly ash and $\mathrm{CaCO}_{3}$ ) with the volume fractions $\left(V_{f}\right)$ of $0,5,10,15,20$ and $25 \%$. The fillers were thoroughly mixed using a shear-type mixer, with a speed of $1000 \mathrm{rpm}$ for $30 \mathrm{~min}$ at room temperature. It was then followed by adding epoxy hardener with resin to hardener ratio of $1: 1$ (by weight). The epoxy to hardener ratio based on the manufacturer's recommendation was $1: 1$ or 2:1 (by weight); however, in this study, the ratio of 1:1 was chosen as based on authors preliminary investigation, the mix ratio of 1:1 has the highest tensile lap shear strength of unaged bonded steel joints compared to the ratio range between $1: 1$ and 2:1. The mixture was stirred again until homogeneous, taking about $10 \mathrm{~min}$ and then degassed in a vacuum chamber to release the trapped air during stirring for about $20 \mathrm{~min}$. The mixing and degassing were conducted at room temperature. Difficulties arose when the filler volume fraction was high (20 and $25 \%$ ), as the viscosity of mixture increased. However, the mixture was swayed 

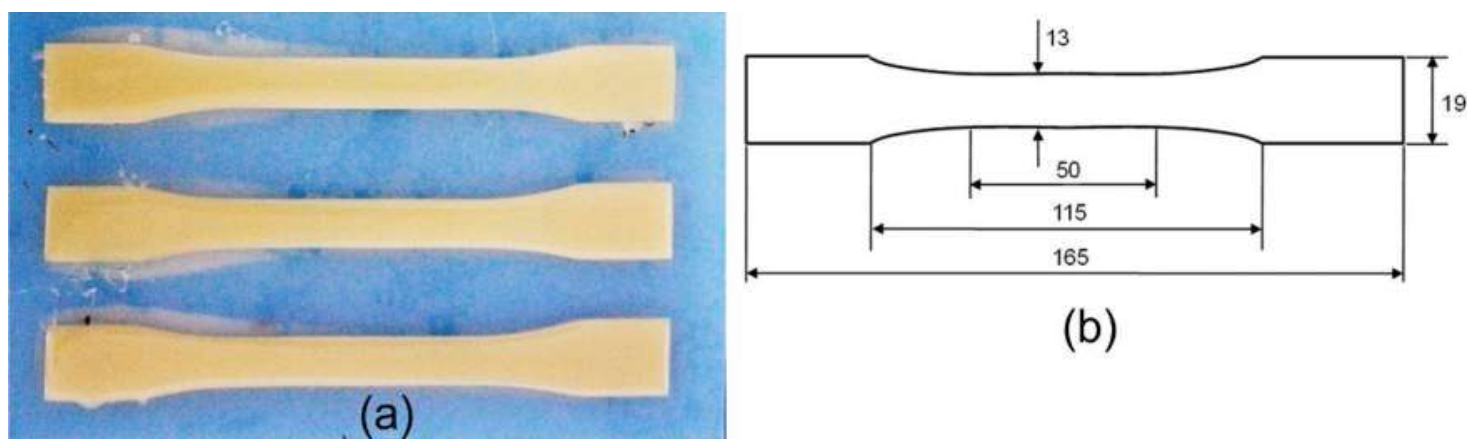

(b)

Fig. 1. (a) Tensile specimens in a silicone rubber mould, and (b) the dimension of the specimen, with the thickness of $3 \mathrm{~mm}$.

during degassing, so the trapped air was quickly released. After the trapped air had been minimized, the mixture was poured into the silicon moulds according to ASTM D638 [29] for the tensile specimen (see Fig. 1). For the water uptake studies, the specimen size was $(30 \times$ $30 \times 2) \mathrm{mm}^{3}$. Following the manufacturer's recommendation, curing of the epoxy systems (neat and filled epoxies) was conducted at room temperature $\left(30^{\circ} \mathrm{C}\right)$ for $24 \mathrm{~h}$. In this study, the final conversion degree of cure was not measured; nevertheless, another researcher, Ali [30], reported that using the similar epoxy and hardener type, the same ratio of epoxy to hardener, and time and curing temperature, the degree of cure was about 0.8 . The effect of fillers on the degree of cure was not investigated in this study; however, Rosso and Ye [31] and Ghaffari et al. [32] reported that adding fillers such as silica and glass flake increased the epoxy degree of cure slightly.

\subsection{Water uptake study}

Water uptake study was conducted on the specimens with the filler volume fractions of $0,5,15$, and $25 \%$. The specimens were immersed in distilled water at a temperature of $50{ }^{\circ} \mathrm{C}$. The aging temperature was below the glass transition $\left(\mathrm{T}_{\mathrm{g}}\right)$ of this epoxy, which was about $60^{\circ} \mathrm{C}$. Nevertheless, as reported in the literature [12,13,33], the $1 \%$ absorbed water could decrease the $\mathrm{T}_{\mathrm{g}}$ in the range of $8-14{ }^{\circ} \mathrm{C}$ (depending on the epoxy system and epoxy to hardener ratio), so at the saturation level, the $T_{g}$ of samples might have been below the aging temperature. The specimen weight and thickness were measured two times on the first day, and once on the following days until the saturation was achieved. Before weighing, the specimen surface was wiped out using a tissue paper. The measurement of the specimen thickness was conducted immediately after the weighing. The weighing and the thickness measurement were carried out using a Kenko digital microbalance and a digital micrometre, respectively. The measurement of the thickness was conducted on the marked area on the specimen to minimize the measurement error.

Most moisture (water) diffusion into a polymer behaves following a Fickian diffusion law, in which the diffusion is driven by a concentration gradient. In one-dimensional diffusion, the total water uptake $\left(M_{t}\right)$ of diffusion into an infinite plate of polymer with a thickness of $2 l$ can be described as in Eq. (1) [34].

$\frac{M_{t}}{M_{\infty}}=1-\frac{8}{\pi^{2}} \sum_{n=0}^{\infty} \frac{1}{(2 n+1)^{2}} \exp \left[\frac{-(2 n+1)^{2} \pi^{2} D t}{4 l^{2}}\right]$

For Fickian diffusion, the linear path of the water uptake vs. time $(t)$ curve, up to approximately $M_{t} / M_{\infty}=0.6$, can be approximated as Eq. (2) [34],

$\frac{M_{t}}{M_{\infty}}=\frac{4}{2 l}\left(\frac{D t}{\pi}\right)^{2}$

therefore, the diffusion coefficient, $D$ can be calculated once the equilibrium water uptake $\left(M_{\infty}\right)$ has been achieved.

For some polymers, the water uptake can deviate from the Fickian diffusion law; however, the initial state of diffusion may follow the Fickian, driven by a concentration gradient. After this, a new uptake process occurs, increasing water uptake with time. Using the Langmuir diffusion model, Carter and Kibler [17] proposed that the absorbed water could be in the form of mobile (free) and bound water. The free water diffusion is concentration-and stress-independent with diffusion coefficient, $D$. There is a probability per unit time that at the same time, the mobile water becomes bound water and vice versa; the bound water becomes mobile water, denoted as $\gamma$ and $\beta$, respectively. If the number of mobile and bound water molecules/unit volume is $n$ and $N$, respectively, at the equilibrium condition, the relation between bound and mobile water is described as in Eq. (3).

$\gamma n=\beta N$

The molecular number densities at the given time, $t$ and at the spatial coordinate $x$ are given in Eqs. (4)-(5).

$D \frac{\partial^{2} n}{\partial x^{2}}=\frac{\partial n}{\partial t}+\frac{\partial N}{\partial t}$

$\frac{\partial N}{\partial t}=\gamma n-\beta N$

To avoid more mathematical solution for Eqs. (4) and (5), as it had been described in [17], in here, the solution for the total water uptake and the other parameters are given as in Eqs. (6)-(8).

$M_{t}=M_{\infty}\left\{\left(\frac{\beta}{\gamma+\beta}\right) e^{-\gamma t} y(t)+\left(\frac{\beta}{\gamma+\beta}\right)\left(e^{-\beta t}-e^{-\gamma t}\right)+\left(1-e^{-\beta t}\right)\right\}$

$y(t)=\left\{1-\frac{8}{\pi^{2}} \sum(2 n+1)^{-2} \exp \left[-(2 n+1)^{2} \kappa t\right]\right\}$

$\kappa=\pi^{2} D /(2 l)^{2}$

When $\beta /(\gamma+\beta)=1$ or $\gamma=0$, Eq. (6) is the same as the Fickian diffusion model. When the exposure time is short and $K t$ is less than 0.7 , Eq. (6) approximates to Eq. (9).

$M_{t}=\frac{4}{\pi^{3 / 2}}\left(\frac{\beta}{\gamma+\beta} M_{\infty}\right) \sqrt{\kappa t}$

When the exposure time is long and $K t$ is larger than 1 , Eq. (6) approximates to Eq. (10).

$M_{t}=M_{\infty}\left[1-\frac{\gamma}{\gamma+\beta} e^{-\beta t}\right]$

\subsection{Tensile testing}

The tensile testing was carried out on the dry and wet specimens. For dry condition, the volume fractions for the tensile test were 5,10 , 15,20 and $25 \%$, while for wet condition, the volume fractions were selected at 5, 15 and $25 \%$ (as representatives). For wet condition, the specimens had been aged in distilled water at a temperature of $50{ }^{\circ} \mathrm{C}$ for 

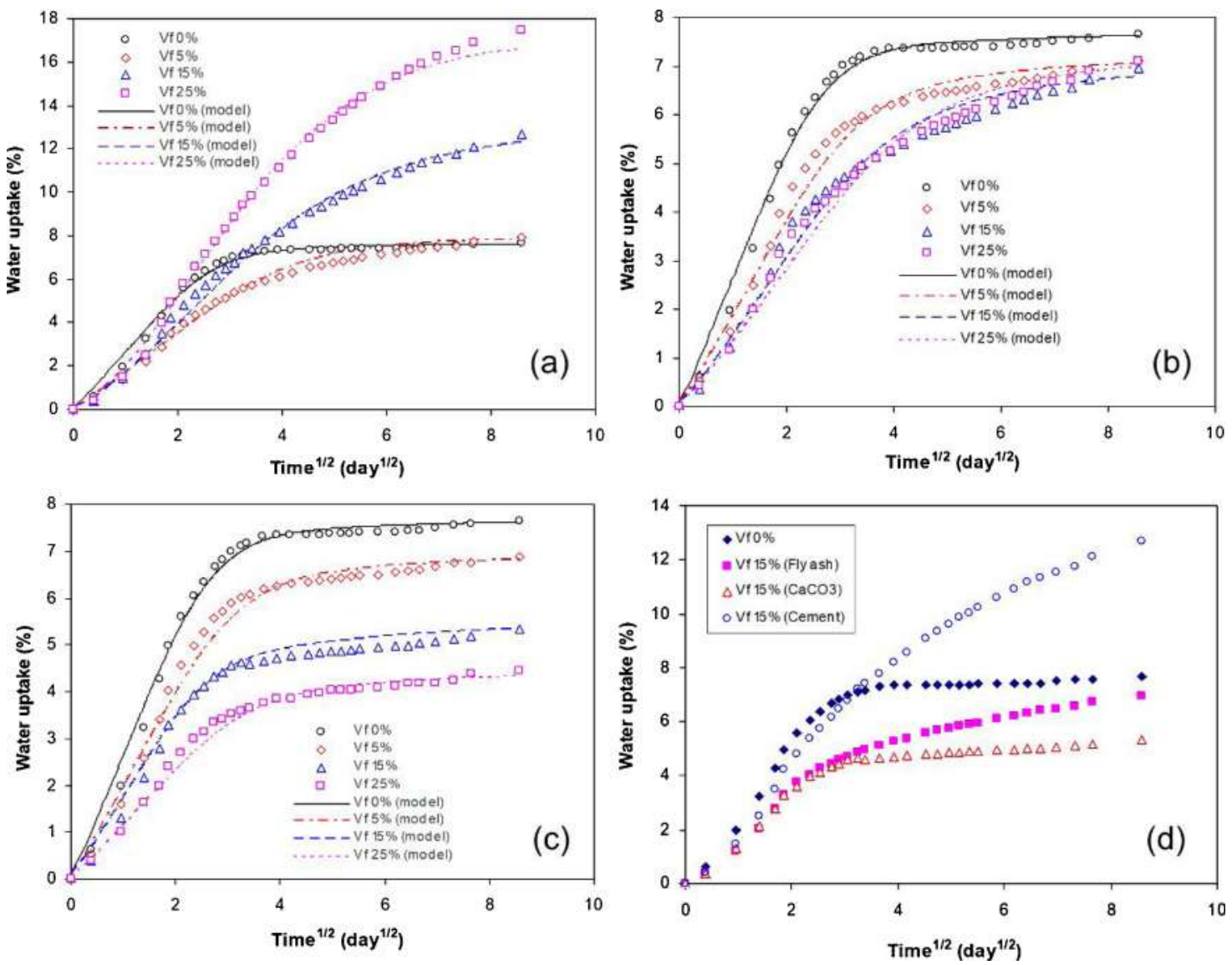

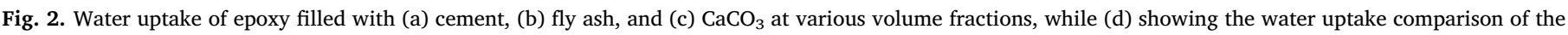
three filled epoxies at a volume fraction of $15 \%$.

30 days. Based on the water uptake of neat epoxy (discussed later in Subsection 3.1), after 30 days, it was estimated that the water content of the tensile specimen had reached the saturation level. The mechanical testing was carried out using a Tensilon universal testing machine with a load capacity of $10 \mathrm{kN}$. The displacement rate for the tensile tests was $5 \mathrm{~mm} / \mathrm{min}$, according to ASTM D638 [29].

\subsection{Scanning electron microscopy (SEM)}

The scanning electron microscopy was conducted on the tensile fracture specimens after both dry and wet tests. The scanning was conducted using a JEOL 630 LA machine, with an operating voltage of $10 \mathrm{kV}$. Before scanning, the specimen surface was coated using a thin gold layer by a sputtering method.

\section{Results and discussion}

\subsection{Water uptake}

Fig. 2 shows the water uptake of filled epoxy systems at various volume fractions, while the diffusion parameters are shown in Table 1. It is worth noting that the reactivity to water from the highest to the lowest is cement, fly ash, and $\mathrm{CaCO}_{3}$. As can be seen in Fig. 2a, the water uptake behavior of cement-filled epoxy changed/deviated from that of neat epoxy, and the deviation was evident at high volume fraction. In all volume fractions, initially, cement particles acted as an effective barrier for water absorption shown by lower water uptake compared to that of neat epoxy, but it then tended to absorb more water with increasing time. At the early stage of diffusion, free volume controlled the water diffusion (Fickian diffusion), but after water reached the cement particles, the hydration reaction took place and absorbed additional water. This behavior could be described using superposition of two Fickian diffusions (dual-Fickian), with two different diffusivities and two equilibrium water uptakes [19]. The diffusion rate of the first Fickian diffusion is higher than the second diffusion, but the equilibrium water uptake of the second diffusion is higher than the first equilibrium water uptake. This water uptake model was not reported here; however, it is of interest for the future works. In this study, a Carter and Kibler's model was utilized to model the water uptake behavior (see Subsection 3.2).

At low cement volume fraction (5\%), up to about 50 days, the water uptake was lower than the neat epoxy, and after that, the water uptake slightly went up beyond that of the neat epoxy. At higher volume fractions (15 and $25 \%$ ), the water uptake of cement-filled epoxy had been higher than that of the neat epoxy at a shorter time, about 9 and 4 days for the volume fractions of 15 and $25 \%$, respectively. The phenomena could be explained as follows. At the $5 \%$ cement content, the particle interspacing distance was quite larger than that of at high filler content (15 dan $25 \%$ ), so at the beginning of water absorption, water filled the free volume and interacted with the epoxy network before reaching the cement particle. At this stage, the cement particle mainly acted as a barrier for water diffusion. However, as the aging time increased longer than about 16 days, the absorbed water might start to react with the cement particles, so more water was required for this reaction and increased the water uptake. The water uptake was slightly higher than the equilibrium water uptake of neat epoxy after about 50 days. Meanwhile, for high cement content, the particles interspacing distance was smaller than that of the $5 \%$ cement content. As results, initially, cement particle also acted as a good barrier better than that of $5 \%$ cement. However, as the time for reaching the cement particle was 
Table 1

Water uptake properties of epoxy systems.

\begin{tabular}{|c|c|c|c|c|c|c|}
\hline Materials & $\mathrm{V}_{\mathrm{f}}(\%)$ & $\mathrm{W}_{\mathrm{f}}(\%)$ & $\mathrm{M}_{\infty}^{\mathrm{c}}(\%)$ & $\left(1-\mathrm{W}_{\mathrm{f}}\right) \mathrm{M}_{\infty}{ }^{\mathrm{m}}(\%)$ & $\mathrm{W}_{\mathrm{f}} \mathrm{M}_{\mathrm{f}}(\%)$ & $\mathrm{D}\left(\mathrm{mm}^{2} /\right.$ day $)$ \\
\hline Neat epoxy & 0 & 0 & $7.39 \pm 0.11$ & 7.390 & 0.000 & $0.103 \pm 0.007$ \\
\hline \multirow[t]{3}{*}{ Cement-filled epoxy } & 5 & 12 & $7.93 \pm 0.15$ & 6.472 & 1.454 & $0.049 \pm 0.007$ \\
\hline & 15 & 32 & $11.79 \pm 0.22$ & 5.008 & 6.782 & $0.022 \pm 0.000$ \\
\hline & 25 & 47 & $16.89 \pm 0.28$ & 3.892 & 12.999 & $0.016 \pm 0.002$ \\
\hline \multirow[t]{3}{*}{ Fly ash-filled epoxy } & 5 & 10 & $7.10 \pm 0.27$ & 6.648 & 0.452 & $0.069 \pm 0.003$ \\
\hline & 15 & 27 & $6.97 \pm 0.12$ & 5.377 & 1.593 & $0.049 \pm 0.003$ \\
\hline & 25 & 41 & $7.11 \pm 0.23$ & 4.329 & 2.781 & $0.026 \pm 0.004$ \\
\hline \multirow[t]{3}{*}{$\mathrm{CaCO}_{3}$-filled epoxy } & 5 & 12 & $6.87 \pm 0.13$ & 6.516 & 0.354 & $0.077 \pm 0.010$ \\
\hline & 15 & 31 & $5.39 \pm 0.00$ & 5.098 & 0.292 & $0.071 \pm 0.011$ \\
\hline & 25 & 46 & $4.37 \pm 0.01$ & 3.996 & 0.378 & $0.071 \pm 0.013$ \\
\hline
\end{tabular}

shorter than that of the $5 \%$ cement content, the absorbed water was immediately contacted and reacted with cement. This lead to increase the water uptake faster and to be higher than that of neat epoxy after about 9 dan 4 days, respectively for the 15 and $25 \%$ cement contents. Moreover, cement hydration caused a chemical shrinkage to about $1 \%$ after 28 days [35] that could develop voids around the cement particles. The voids might also highly contribute to the high increase in water uptake, mainly when the content was high. The hydrated cement and voids will also affect the water desorption and reabsorption behavior, and this will be of interest for the future works, together with other fillers (fly ash and $\mathrm{CaCO}_{3}$ ).

As seen in Table 1, with the increase of volume fraction, the diffusion rate of cement-filled epoxy tended to decrease, and the equilibrium water uptake increased significantly.

Compared to the neat epoxy, the decrease of diffusion rate at the volume fractions of 5, 15 and $25 \%$ was 52,79 and $84 \%$, respectively; meanwhile, the increase of water uptake at the volume fractions of 5 , 15 , and $25 \%$ was 7,59 , and $128 \%$, respectively. As cement was reactive to water; therefore, having contacted with water, cement and water reacted to form calcium silicate hydrates. The hydration reaction used most of the absorbed water, so water was likely resided surrounding the cement particles rather than in the microvoids of polymer chains. Chow et al. [36] and Chow [37] respectively showed that adding organo-monmorillonite (OMMT) in polyamide 6/polypropylene nanocomposites and glass fibre reinforced epoxy composites increased the water uptake as the water reacted with the OMMT. Other researchers, Capiel et al. [38], showed that the chemical reaction in the epoxy network, such as hydrolysis, consumed water, and increased the water uptake. The more cement particles in the polymer required the more water for the reaction, so it was expected that the water uptake continued to increase with increasing cement volume fraction. Moreover, at high volume fraction, the particles tended to agglomerate and created more voids, and then further increased the water uptake [4,23]. Lekatou et al. [39] reported that the agglomeration occurred when the volume fraction of filler was higher than $15.7 \%$. Beyond this volume fraction, the water uptake tended to increase faster as the absorbed water could segregate from the polymer chains to form a water cluster. Because the absorbed water was mostly used for the cement-water reaction; therefore, the time for reaching the saturation increased, slowing down the diffusion rate significantly. The water transport was likely hindered because the cement particles were functioned as a water trapper.

Hydration cement could produce $\mathrm{Ca}(\mathrm{OH})_{2}$, and this product reaction could induce a hydrolytic reaction of polyaminoamide hardener in the aged cement-filled epoxy. The existence of hydrolytic reaction is typically shown by the high increase and then followed by the decrease of water uptake after the equilibrium was reached due to leaching $[13,38]$. However, in this study, as the water uptake of cement-filled epoxy still increased with time, the existence of the hydrolytic reaction of epoxy components has not been observed.

For the fly ash-filled epoxy, as seen in Fig. 2b, it seemed that the increase of volume fraction was able to decrease the water uptake; however, it seemed that the decrease reached the maximum at the volume fraction of $15 \%$. When the volume fraction was higher than 15 $\%$ for a longer aging time, the water uptake tended to increase again, but at the time studied, the water uptake was still lower than that of the neat epoxy. It was possible that at high volume fraction, the particles tended to agglomerate, forming a cluster that was able to absorb more water $[23,39]$. The water uptake behavior deviated from a Fickian diffusion, and the deviation was more noticeable at high volume fraction, similar to that of the cement-filled epoxy. As seen in Table 1, the diffusion rate decreased with the increase of volume fraction. The decrease in the diffusion rate was 33,52 , and $75 \%$ for the volume fractions of 5,15 , and $25 \%$, respectively. At the early stage of diffusion until the knee of the water uptake curve, the difference of water uptake curves was apparent, but when the water uptake approached the saturation, the difference became insignificant. At the equilibrium, the water uptake decreased by about $4 \%$ for all volume fractions compared to the neat epoxy. There is an indication that for longer aging time, the water uptake for high fly ash content will be going up beyond the water uptake of neat epoxy. However, in this study, the time when water uptake was beyond the equilibrium water uptake of neat epoxy had not been obtained as the aging had been stopped for desorption study, which was not reported here. Nevertheless, the absorption-desorptionreabsorption behavior of this filled epoxy becomes of interest for the future works. The continue increase of water uptake for fly ash-filled epoxy might be because fly ash contains some elements that are soluble to water, such as alkalies (mostly sodium (Na), calcium (Ca)) [40], and the mayor compound of silica $\left(\mathrm{SiO}_{2}\right)$. Calcium oxide $(\mathrm{CaO})$ was readily hydrolyzed by water, forming $\mathrm{Ca}(\mathrm{OH})_{2}$, while silica from the fly ash particles reacted slowly to the water, forming silica acid [41]. The acid produced by the silica reaction could increase the water uptake [38].

For the $\mathrm{CaCO}_{3}$-filled epoxy, as seen in Fig. 2c, the water uptake behavior tended to follow Fickian diffusion for all volume fractions. Compared to the neat epoxy, the water uptake decreased with the increase of volume fraction. As seen in Table 1, the diffusion rate decreased as the volume fraction increased, but the diffusion rate at the volume fractions of 15 and $25 \%$ was about the same. The decreases in the diffusion rate were 25,31 , and $31 \%$ for the volume fractions of 5 , 15 , and $25 \%$, respectively. Meanwhile, the decreases in equilibrium water uptake were 7,27 , and $41 \%$ for the volume fractions of 5,15 , and $25 \%$, respectively. $\mathrm{CaCO}_{3}$ is insoluble to pure (distilled) water and also may not affect the polarity of the epoxy network; however, they may decrease the crosslink density of epoxy, as also reported by $[42,43]$. In this case, $\mathrm{CaCO}_{3}$ particles provided tortuosity of water diffusion that decreased the water uptake. The high decrease of water uptake at the low $\mathrm{CaCO}_{3}$ content (up to $15 \%$ ) was not shown at the content between 15 and $25 \%$. This was probably due to the agglomeration of the particles beyond the content of $15 \%$, so the agglomerated particles became sites for water clustering. As a result, the decrease of water uptake was not as high as that below the content of $15 \%$. As stated previously [39], the critical volume fraction of particles for 
Table 2

Carter and Kibler's parameters for curve fitting.

\begin{tabular}{|c|c|c|c|c|c|c|c|c|c|c|}
\hline \multirow{2}{*}{$\begin{array}{l}\text { Materials } \\
\text { Filler volume fraction (\%) }\end{array}$} & \multirow{2}{*}{$\begin{array}{l}\text { Neat epoxy } \\
0\end{array}$} & \multicolumn{3}{|c|}{ Cement-filled epoxy } & \multicolumn{3}{|c|}{ Fly ash-filled epoxy } & \multicolumn{3}{|c|}{$\mathrm{CaCO}_{3}$-filled epoxy } \\
\hline & & 5 & 15 & 25 & 5 & 15 & 25 & 5 & 15 & 25 \\
\hline$\beta$ (/day) & 0.036 & 0.036 & 0.036 & 0.048 & 0.036 & 0.036 & 0.036 & 0.036 & 0.036 & 0.036 \\
\hline$\gamma$ (/day) & 0.002 & 0.006 & 0.036 & 0.072 & 0.006 & 0.012 & 0.012 & 0.004 & 0.006 & 0.006 \\
\hline$\beta /(\gamma+\beta)$ & 0.95 & 0.85 & 0.50 & 0.40 & 0.85 & 0.75 & 0.75 & 0.90 & 0.85 & 0.85 \\
\hline
\end{tabular}

agglomeration to occur was $15.7 \%$. Beyond this critical volume fraction, the particles, in this case, $\mathrm{CaCO}_{3}$, tended to make a chain (agglomeration), so the barrier effect of particles reduced.

Fig. $2 \mathrm{~d}$ shows the comparison of water uptake for the neat and the three filled epoxies at the volume fraction of $15 \%$ as representative of the other volume fractions. It was observed that the water uptake behavior of the three filled epoxies differed due to different reactivity to water. It was clear that cement (the most reactive filler) had the highest water uptake, subsequently followed by fly ash (semi reactive) and $\mathrm{CaCO}_{3}$ (unreactive). Initially, the water uptake $v s$. aging time curves slightly differed for all epoxies systems; however, with increasing aging time, they took different routes. The water uptake behavior of $\mathrm{CaCO}_{3}-$ filled epoxy similar to that of the neat epoxy, which was a pseudoFickian; however, water uptake of $\mathrm{CaCO}_{3}$-filled epoxy was lower. Meanwhile, water uptake behavior of epoxy filled with reactive (cement) and semi reactive (fly ash) fillers deviated from a Fickian diffusion. For the reactive filler, the water uptake tended to be higher than that of neat epoxy, particularly at high volume fraction.

To indicate the reactivity of filler to water, the mixture of rule, $M_{\infty}{ }^{c}$ $=W_{f} M_{f}+\left(1-W_{f}\right) M_{\infty}{ }^{m}$, was applied to calculate the absorbed water by filler, where $M_{\infty}{ }^{c}, W_{f}, M_{\infty}{ }^{m}$, and $M_{f}$ are the equilibrium water uptake of the composites, the filler weight fraction, the equilibrium water uptake of epoxy matrix and the water uptake of filler, respectively. As the degree of curing was the same for all samples, the water uptake of matrix was assumed to be the same for each sample. By taking the densities of cement, fly ash, $\mathrm{CaCO}_{3}$ and the epoxy of 3.1, 2.44, 2.93 and $1.15 \mathrm{~g} / \mathrm{cm}^{3}$, respectively, to correlate the $V_{f}$ to $W_{f}$, the calculated water uptakes of fillers are shown in Table 1. Under the same filler content, it was observed that the order of absorbed water by filler from low to high was $\mathrm{CaCO}_{3}$, fly ash and cement. Hence, the order of the absorbed water also indicated the order of the reactivity of filler to water. For the reactive fillers (cement and fly ash), the absorbed water by filler tended to increase with the increase of filler content. By plotting the water uptake of filler vs. the filler content (not shown here), it was found that the amount of water absorbed per percentage of filler at the content of $25 \%$ was higher than those at the contents of 5 and $10 \%$. Meanwhile, for the less reactive filler $\left(\mathrm{CaCO}_{3}\right)$, the water uptake of filler decreased from the content of 5-10\% and then increased again at the content of $25 \%$, higher than that at the content of $5 \%$. Hence, for all fillers, the high increase of absorbed water at the content of $25 \%$ compared to the content of 5 and $10 \%$ further confirmed that there were agglomerations of the particles, which became sites for water clustering. In the case of cement-filled epoxy, the hydration reaction caused the particles to chemically shrink [35], resulting in the voids formed between filler and matrix and in the agglomerated particles. The formed voids further added pathways for water diffusion and then increased the absorbed water, particularly at the filler content of $25 \%$.

The difference in the water uptake behavior of those filled epoxies indicated that the less and more reactive fillers might have modified the polymer segment around the fillers differently. Preliminary investigations using a Fourier Transform Infrared (FTIR) spectroscopy to indicate the interaction of filler-matrix, water-filler and water-matrix can be found in the Supplementary material. Nonetheless, further study on the interaction of those type of fillers is of interest for the future works.

\subsection{Model of water uptake}

In this study, Carter and Kibler's diffusion model was utilized to characterize the diffusion behavior. The diffusivity and the equilibrium water uptake of this model are shown in Table 1. The Carter and Kibler's parameters related to the probability of mobile water became bound water $(\gamma)$ and bound water became mobile water $(\beta)$ were determined. As pointed by Popineau et al. [44], firstly, the ratio of $\beta /(\gamma+$ $\beta$ ) was determined at the pseudo equilibrium for each experimental data. After that, the value of $\beta$ was determined by obtaining the best fitting of the Eqs. (6)-(8) to the experimental data, then the value of $\gamma$ was obtained by solving the $\beta /(\gamma+\beta)$. The results are shown in Table 2 .

Based on the Carter and Kibler's parameters, good fits were obtained between the model and the experimental water uptake data, as seen in Fig. 2. For neat epoxy, the $\beta /(\gamma+\beta)$ is close to unity, which meant that the water uptake behavior tended to follow the classical Fickian diffusion law (pseudo-Fickian). The slight second stage of absorption at a longer aging time was observed that might be caused by an increasing degree of water clustering (mobile water) [44]. Here, as the $\beta$ dominated, most of the absorbed water was likely to be mobile water. For the cement-filled epoxy, the $\beta /(\gamma+\beta)$ decreased with the increase of cement content, or the $\gamma$ increased and became higher than the $\beta$ value at the cement volume fraction of $25 \%$. This was expected as according to the water uptake data, the water uptake increased with the increase of cement content, and the absorbed water reacted with the cement particles. In this case, the reacted water was considered becoming bound water; therefore, the $\gamma$ value increased with increasing the cement particles content, as more water was needed for the hydration reaction. For the fly ash-and $\mathrm{CaCO}_{3}$-filled epoxies, the trend of increasing $\beta /(\gamma+$ $\beta$ ) ratio with the increase of volume fraction was similar, where most water remained as mobile water. However, the $\gamma$ value of fly ash-filled epoxy was slightly lower, indicating that the number of bound water in the fly ash-filled epoxy was higher than in the $\mathrm{CaCO}_{3}$-filled epoxy. The $\mathrm{CaCO}_{3}$ did not react with water; therefore, it did not consume water as the cement and fly ash did.

\subsection{Swelling}

Fig. 3 shows the swelling strain vs. water uptake curves of epoxy systems at various filler volume fractions. The coefficients of moisture expansion (CME), which are the slopes of the swelling strain vs. water content curves, are shown in Table 3. For all filled epoxies, it seemed that the swelling strain was not linear over the water content. The swelling was low at the beginning of water uptake and then increased approaching the saturation level. According to Adamson [45], this has been confirmed by other researchers [46,47], in the beginning, most of the absorbed water filled the free volume, rather than resided within the polymer chains. Only water that resided within the polymer chain caused the swelling, so at the beginning, the swelling was small. When the free volume had been filled with water, the absorbed water tended to reside within the polymer chains and then disrupted the van der Walls and hydrogen bonds. The scission of van der Walls and hydrogen bonds caused the relative increase of volume to be the same as the relative volume of the absorbed water.

For all types of fillers, at the same water content, swelling strain tended to increase with the increase of volume fraction. Cates [48] 

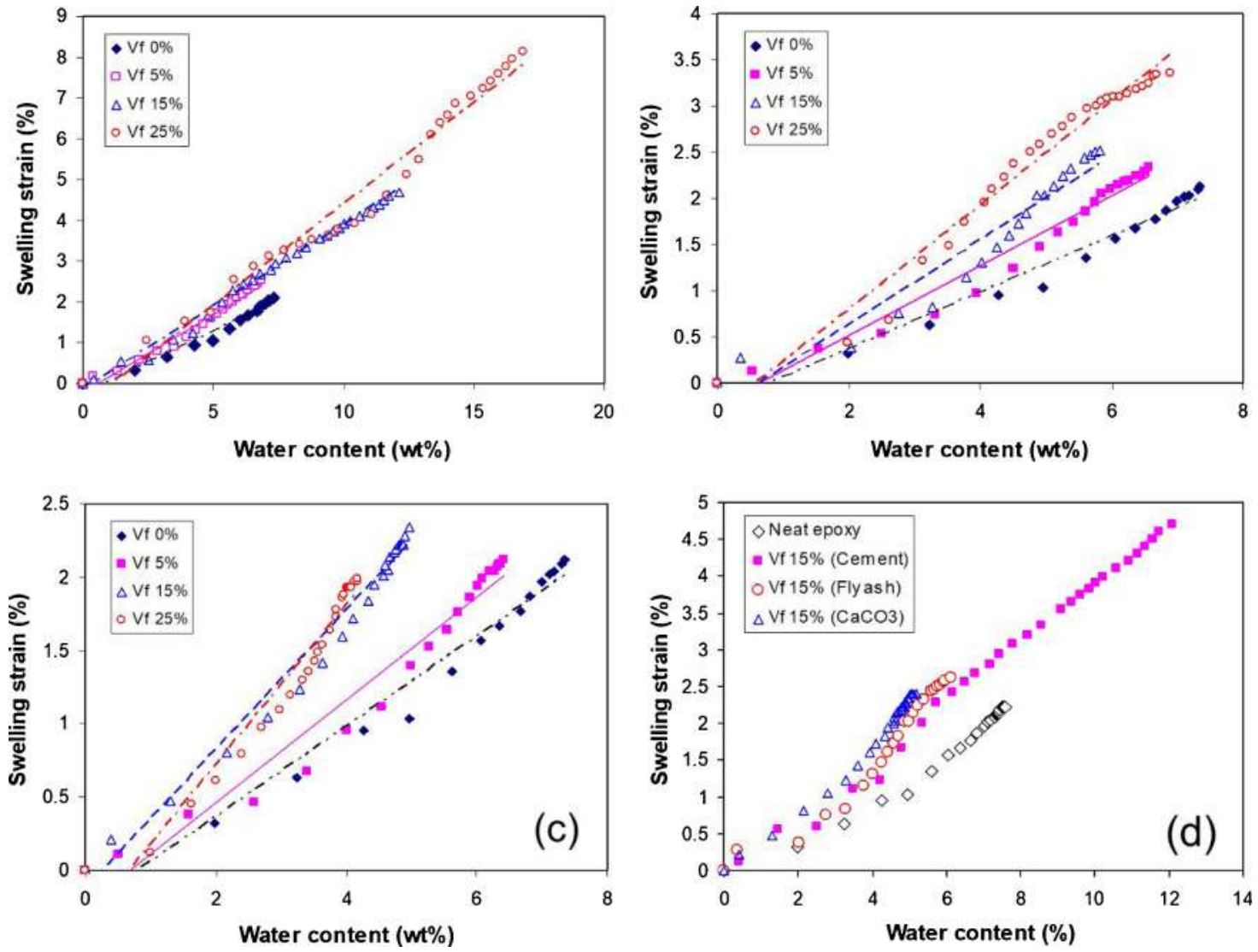

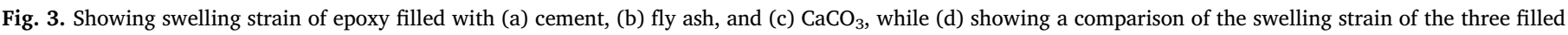
epoxies at the volume fraction of $15 \%$.

showed that the swelling of poly(N-isopropylacrylamide) hydrogels increased when the crosslink density decreased, while Yan et al. [49] showed the similar results on the multi-walled carbon nanotubes-filled poly(glycerol sebacate) elastomer. Adding micro filler into the epoxy could decrease the crosslink density [50,51], so the filled epoxy tended to have low crosslink density. As a result, the swelling strain also tended to increase with the increase of filler volume fraction, and this agreed well with the study of Pittayavinai et al. [52] on the natural rubber filled with carbon and sulfur. As seen in Fig. 3a, the swelling strain for the cement-filled epoxy at the various volume fractions seemed very close; however, they were higher than that of the neat epoxy, as expected. It seemed that most water resided in the free volume created by cement particles, so the swelling strain rate (as a function of volume fraction) was low. As seen in Table 3, the CME of cement-filled epoxy at the volume fractions of 5 and $15 \%$ was the same, but it increased at the volume fraction of $25 \%$. For the fly ash- and $\mathrm{CaCO}_{3}$-filled epoxies (see Figs. 3b and 3c, respectively), the effect of volume fraction on the swelling strain seemed to become apparent. The CME for both epoxy systems increased with the increase of volume fraction, but the CME for $\mathrm{CaCO}_{3}$-filled epoxy was slightly higher than that of the fly ash-filled epoxy. It could be due that most of the absorbed water in the $\mathrm{CaCO}_{3}$ - filled epoxy resided within the polymer chains, whereas in the fly ashfilled epoxy, some water was required to hydrolyze fly ash particles.

The comparison of swelling strain vs. water content curves of the neat epoxy and the filled epoxies at the volume fraction of $15 \%$ is shown in Fig. 3d. It was seen that at the volume fraction of $15 \%$, the order of CME from the lowest to highest was neat epoxy, cement-, fly ash- and $\mathrm{CaCO}_{3}$-filled epoxies. However, the order was valid at the volume fraction beyond $15 \%$, as at the volume fraction of $5 \%$, the CME of the three filled-epoxies was about the same.

\subsection{Tensile properties of filled epoxies}

Fig. 4 shows the typical stress-strain curves of epoxy systems in the dry and wet conditions, selected at the filler volume fraction of $15 \%$. In the dry condition, as seen in Fig. 4a, the curves of filled epoxies were dominated by the elastic region, but for neat epoxy, the plastic deformation was significant; it was about $67 \%$ higher than that of filled epoxies at the volume fraction of $15 \%$. In wet condition (Fig. 4b), where the epoxy systems had been saturated by water, the significant plastic deformation was observed, shown by the considerable increase of strain at fracture, compared to that in dry condition. For example,

Table 3

The coefficient of moisture expansion of epoxy systems.

\begin{tabular}{lll}
\hline Filler volume fraction (\%) & \multicolumn{2}{l}{ Coefficient of moisture expansion $(/ \mathrm{wt} \%)$} \\
\cline { 2 - 3 } & Cement-filled epoxy & Fly ash-filled epoxy \\
\hline 0 & $0.0034 \pm 0.0002$ & $0.0034 \pm 0.0002$ \\
5 & $0.0039 \pm 0.0003$ & $0.0038 \pm 0.0002$ \\
15 & $0.0039 \pm 0.0009$ & $0.0046 \pm 0.0002$ \\
25 & $0.0049 \pm 0.0003$ & $0.0052 \pm 0.0011$
\end{tabular}



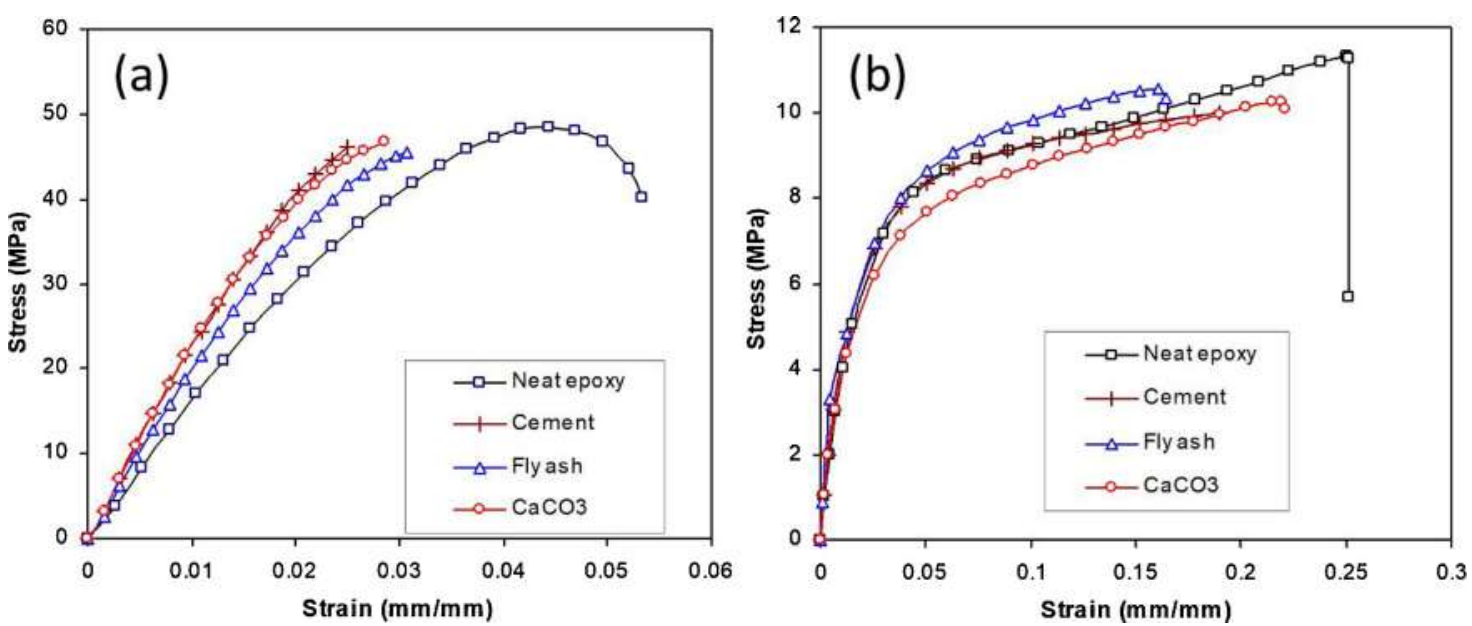

Fig. 4. Typical tensile stress-strain of epoxy systems in (a) dry and (b) wet conditions at the filler volume fraction of $15 \%$.

the increase of strain at fracture in wet condition was about $560 \%$ and $535 \%$ for neat epoxy and fly ash-filled epoxy, respectively. It has been well known that water induces plasticization of the polymer, decreasing the stiffness and glass transition temperature. As stated previously $[12,13,33]$, the $\mathrm{T}_{\mathrm{g}}$ can decrease up to $8-14{ }^{\circ} \mathrm{C}$ per $1 \%$ the absorbed water. Because the $\mathrm{T}_{\mathrm{g}}$ of dried epoxy systems was about $60{ }^{\circ} \mathrm{C}$ and the aged samples had reached the saturation level (most of water contents were higher than $4.5 \%$ ), it was high likely that the $\mathrm{T}_{\mathrm{g}}$ of aged specimens had decreased to below the aging temperature. Therefore, the high increase of ultimate elongation for the aged specimens was possible due to the aged specimens had turned to the viscoelastic behavior (in the rubbery state).

Fig. 5 shows the tensile properties of epoxy systems in dry and wet conditions. For wet condition, the filler content was selected at the volume fractions of 5, 15 and $25 \%$ (as representatives). In dry condition, as seen in Fig. 5a, the elastic modulus of filled epoxies increased linearly with the increase of filler volume fraction. This is consistent with the rule of mixture, where adding inorganic filler that has higher elastic modulus into low elastic modulus of polymeric material increases the composite elastic modulus, as also reported by Fu et al. [53]. In general, the cement-filled epoxy had the highest trend of elastic modulus followed by $\mathrm{CaCO}_{3}$ - and fly ash-filled epoxies, which was consistent with the order of the elastic modulus of cement (135 GPa) [54], $\mathrm{CaCO}_{3}$ (35 GPa) [55], and fly ash particles (17 GPa) [56]. The increase of elastic modulus of filled epoxies if being compared to the neat epoxy was about $78 \%$ at the volume fraction of $25 \%$. Other researchers [53,57] reported that the elastic modulus of the filled polymer was not sensitive to the interface interaction between the filler particle and the matrix, so these results were consistent with the published literature. Our previous study [26], using the same filler but with different epoxy systems, showed similar results. Besides, there is a reliable dependent between particle shape and the elastic modulus [58], so because the $\mathrm{CaCO}_{3}$ and cement particles shape is irregular, not spherical as that for fly ash particles, it is expected that the elastic modulus of $\mathrm{CaCO}_{3}$ and cement-filled epoxy are higher than that of fly ash-filled epoxy. Nevertheless, as the aspect ratio of those fillers was not significantly different (close to unity), the slight difference of measured elastic modulus of the three filled epoxies was observed for all particle loadings.

In contrast to the elastic modulus, as seen in Fig. 5b, the tensile strength tended to decrease with the increase of filler volume fraction, for all types of filler. The order of decreasing trend from the lowest to the highest was the following: the cement-, fly ash- and the $\mathrm{CaCO}_{3}$-filled epoxies. At the volume fraction of $10 \%$, the tensile strength of fly ashfilled epoxy is the highest. The similar results were reported by Dharmalingam et al. [59] for fly ash-filled epoxy and silica-filled epoxy [53], which could be caused by the well-dispersed of the particles. For the tensile strength, the particle size, interface strength between filler particles and the matrix, and the particle loading contributed to the composite strength [53]. As reported by Pukanszky and Voros [60], for the micron-sized particles, the tensile strength tended to decrease with the increase of particle loading, which was consistent with these results. Up to the particle loading of $10 \%$, the tensile strength of all three fillers decreased by up to $5.6 \%, 1 \%$, and $8.7 \%$ for the cement-, fly ash- and the $\mathrm{CaCO}_{3}$-filled epoxies, respectively. The decrease continued up to the volume fraction of $25 \%$ for the fly- and $\mathrm{CaCO}_{3}$-filled epoxies but for the cement-filled epoxy, the tensile strength tended to remain constant. It was likely that the interface strength of cement-epoxy was higher than those of the fly ash- and $\mathrm{CaCO}_{3}$-epoxies.

The effect of filler on the tensile strength depends on the adhesion of filler-matrix, the stress concentration due to inclusion of filler and defect size/spatial distribution [61]. The good adhesion increases the tensile strength and plays a dominant role, whereas, the stress concentration decreases the tensile strength [61]. Those two factors compete with each other. As reported by Wang et al. [61], the stress concentration at the content of 20-30\% was higher among the other contents. For the low adhesion strength of filler-matrix, for example, fly ash and $\mathrm{CaCO}_{3}$, the much decrease of tensile strength occurred at the volume fraction of 20 and $25 \%$, which agreed with the Wang et al.'s finding. Meanwhile, for the cement-filled epoxy, high adhesion fillermatrix compensated the detrimental effect of stress concentration at the volume fractions of $20-30 \%$. The similar phenomenon was also reported by Spanoudakis and Young [62] that studied the effect of filler content on the tensile strength of epoxy filled with the treated and untreated silica particles.

In the wet condition, as seen in Figs. $5 c$ and $5 d$, the elastic modulus and the tensile strength decreased significantly compared to those in dry condition, for the neat and filled epoxies. Most of the specimens had reached the saturation level; therefore, the plasticization effect played the primary role in the mechanical properties. The positive effect had by the three

fillers on the elastic modulus in dry condition diminished in the wet condition. The tensile strength of filled epoxies also showed a similar trend to that in dry condition, where they tended to decrease with the increase of filler volume fraction. Compared to those in the dry condition, the elastic modulus of neat epoxy decreased by about $73 \%$, while for the filled epoxies, the decrease varied depending on the volume fraction. The minimum and the maximum decrease of elastic modulus respectively occurred at the volume fraction of $5 \%$ (about 55 $\%$ ) for the cement-filled epoxy and at the volume fraction of $25 \%$ (about $84 \%$ ) for the fly ash-filled epoxy. Meanwhile, the average decrease in the tensile strength compared those in dry condition was 

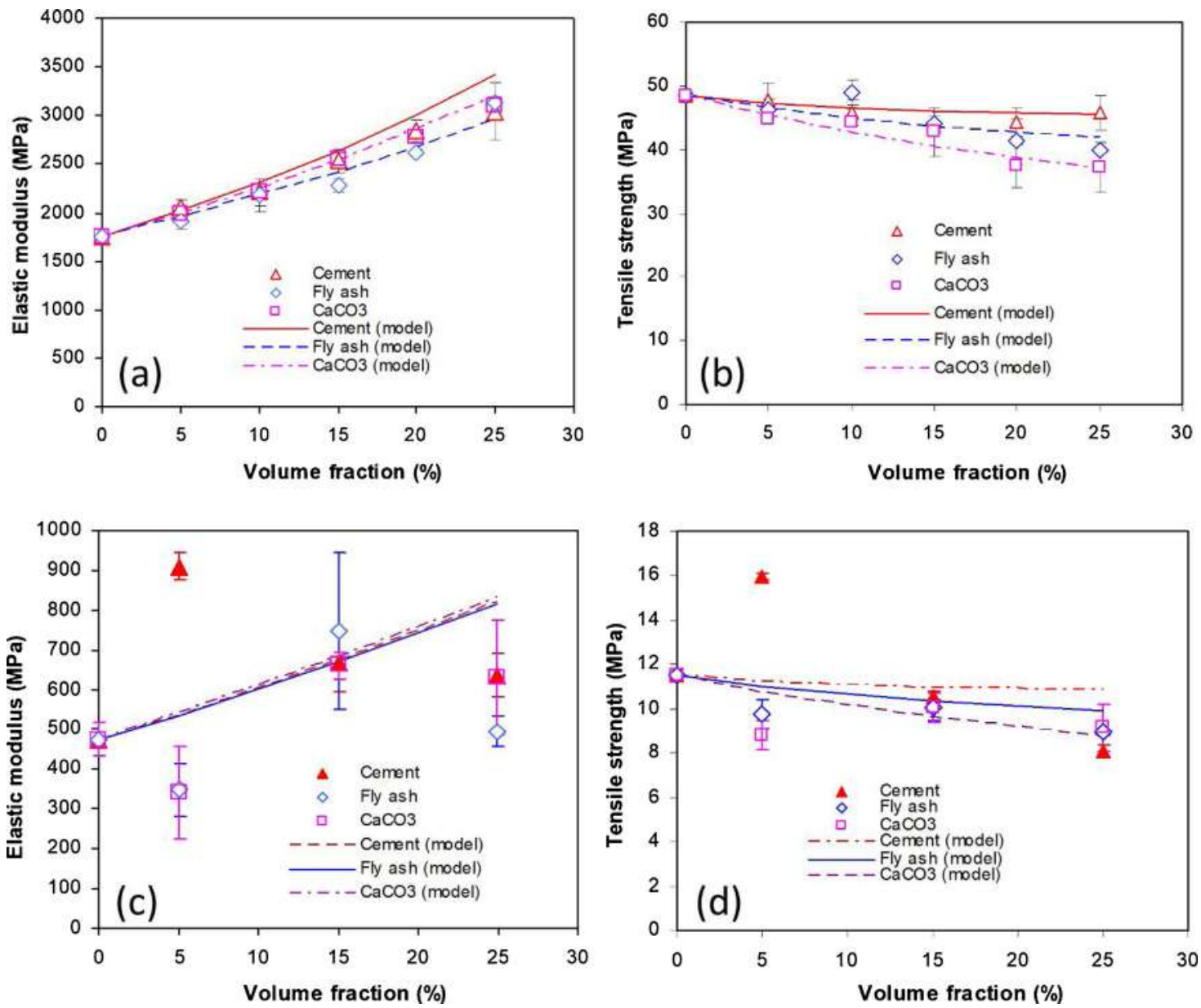

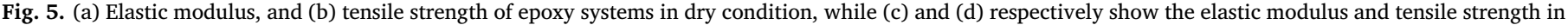
wet condition.

about $77 \%$, regardless of the volume fraction and filler type. The anomaly occurred on the $5 \%$ cement-filled epoxy, where both the elastic modulus and the tensile strength were higher than the neat and the other filers volume fractions. Based on the SEM micrograph (discussed later in the Subsection of 3.6), more dispersed cement particles at the filler content of $5 \%$ was likely to be the cause of the anomaly.

\subsection{Modelling of the effect of filler on the tensile properties}

Several models have been reported to predict the elastic modulus of filled polymer, including Halpin-Tsai's [63,64], and Mori-Tanaka's [65] models. Each model has advantages and disadvantages, depending on factors such as particle shape, particle size, the properties of filler. However, of those models, Halpin-Tsai's model is applicable for most filled polymers as reported by other researchers [66-68]; therefore, the model was used to estimate the elastic modulus in this study.

The Halpin-Tsai's model was described as in Eqs. (11) and (12).

$\mathrm{E}=\frac{1+\xi \eta \mathrm{V}_{\mathrm{f}}}{1-\eta \mathrm{V}_{\mathrm{f}}} \mathrm{E}_{\mathrm{m}}$

$\eta=\frac{\frac{E_{f}}{E_{m}}-1}{\frac{E_{f}}{E_{m}}+\xi}$

Where $V_{f}$ is the volume fraction of particles, $E_{f}$ and $E_{m}$ are the elastic modulus of particle and matrix, respectively, while $\xi$ is a shape factor that depends on the geometry, which is usually 2 for spherical particles.

By assuming strong adhesion between particle and matrix, a model proposed by Pukanszky et al. [69] was applied to model the tensile strength of the filled epoxies $\left(\sigma_{c}\right)$, given in Eq. (13).

$\sigma_{c}=\left[\frac{1-V_{f}}{1+2.5 V_{f}} \sigma_{m}\right] \exp \left(B V_{f}\right)$

Where $\sigma_{m}$ is the strength of the matrix, $V_{f}$ is the volume fraction of particle, and $B$ is an empirical constant, which is dependent on the surface area of particles, particle density, and interfacial bonding energy. $B$ value is 0 for very weak adhesion and can be increased, depending on the adhesion strength.

Using the elastic modulus of cement (135 GPa) [54], fly ash (17 GPa) [56], and $\mathrm{CaCO}_{3}(35 \mathrm{GPa}$ ) [55], the predicted elastic modulus was in good agreement with the experimental data, as shown in Fig. 6 a. Meanwhile, using the $B$ value of $2.85,2.5$, and 2 for cement, fly ash, and $\mathrm{CaCO}_{3}$, respectively, the predicted tensile strength also agreed well with the experimental data (Fig. 5b). Referring to the $B$ value, it seemed that the order of adhesion strength between particle and matrix from the highest to the lowest was cement, fly ash, and $\mathrm{CaCO}_{3}$.

In wet condition, the elastic modulus of cement decreased to $25 \mathrm{GPa}$ [54] due to hydration reaction, while the elastic modulus of the other particles was similar to those in dry condition, by assuming there was no significant reaction with water that influenced the elastic modulus. As the absorbed water caused deterioration of the adhesion strength, $B$ values reduced to $2,1.8$, and 1.5 for cement, fly ash, and $\mathrm{CaCO}_{3}$, respectively. For the cement-filled epoxy, having reacted with water, the cement particles could chemically shrink up to $1 \%$ [35], so voids were likely formed between the particle and epoxy matrix. The voids then degraded the interfacial strength and macroscopically the tensile properties of the aged composites, particularly at the high filler content 

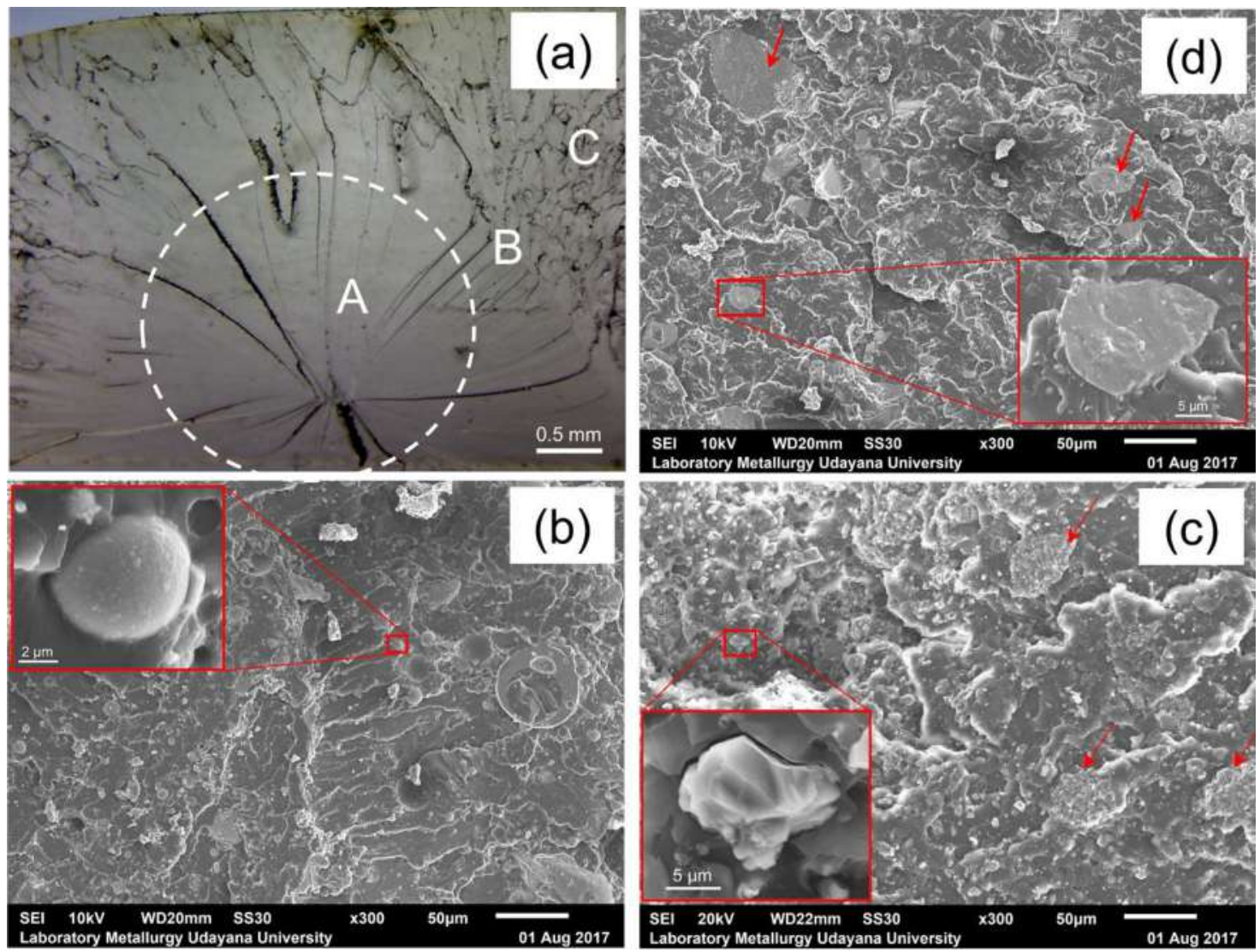

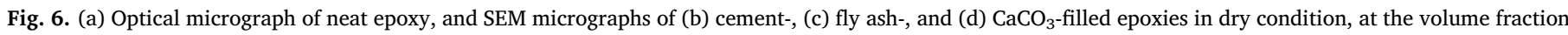
of $15 \%$.

(see Figs. 5c-d). In dry condition, the Halpin-Tsai's model could well predict the elastic modulus with the volume fraction for the three epoxy systems; however, in wet condition, the model failed to do so (see Fig. 5c). Similarly, the Pukanszky et al.'s model could not well predict the tensile strength with the increase of volume fraction, see Fig. $5 \mathrm{~d}$. The failure of those models to predict the effect of volume fraction on the elastic modulus and tensile strength could be due to the excessive matrix deformation and very weak interfacial bonding between particle and matrix.

\subsection{Morphologies of fracture surfaces}

Fig. 6a and Figs. 6(b-d) respectively show the optical fracture surface of neat epoxy and SEM micrograph of the fracture surfaces of filled epoxies in the dry condition, at the volume fraction of $15 \%$. It was observed that for the neat epoxy (Fig. 6a), the fracture surface consisted of three regions: mirror, mist, and final fracture regions, indicated by marks A (in the dashed white circle), B and C respectively, which was typical for of brittle fracture [70,71]. In a brittle fracture, the surface roughness, as well as the speed of crack propagation, increased continuously from the mirror to the final fracture regions [70,71]. For the cement-filled epoxy (Fig. 6b), it was seen that the cement particles (indicated by red arrows) were well bonded with the matrix and the fracture occurred across through the particles. The particle shape was irregular, so it could act as an obstacle for matrix deformation and crack propagation.

For the fly ash-filled epoxy, as seen in Fig. 6c, most fly ash particles were well bonded with the matrix, indicated the fly ash particle attached in the matrix, but few particles were also detached from the matrix shown by holes. Nevertheless, for the well-bonded fly ash particles, the crack may propagate through about the poles on the fly ash particles, shown by a very thin epoxy layer attached on the fly ash particles. It was also seen that the fracture surface was rough, showing crack pinning, crack deflection, and branching. Those features were also observed in the spherical silica-filled epoxy [61]. For the $\mathrm{CaCO}_{3}$ filled epoxy, the fracture surface was rough. The $\mathrm{CaCO}_{3}$ particles seemed to debond from the matrix, as shown by the void around the particles. It was also seen in Fig. 6d that there was a tendency for particles to agglomerate, shown by red arrows. The agglomeration of $\mathrm{CaCO}_{3}$ particles acted as loci of failure that could further decrease the mechanical properties.

Fig. 7 shows the SEM micrographs of fracture surfaces of epoxy systems in the wet condition. As seen in Fig. 7a, the fracture surface of neat epoxy was very smooth, dominated by the mirror region. The smooth feature might be caused by excessive plastic deformation after absorbing water. Fig. $7 \mathrm{~b}$ and $\mathrm{c}$ respectively show the SEM micrographs of $5 \%$ and $15 \%$ cement-filled epoxy. It appeared that at the volume fraction of $5 \%$, the dispersion of cement particles was better than at the volume fraction of $15 \%$. The good dispersion of the particles may explain the highest tensile properties of cement-filled epoxy in this wet condition. The fracture surface was very rough, and the appearance of the cement particles was different compared to that in the dry condition. This indicated that the cement particles had changed due to reaction with water, forming calcium silicate hydrates. It appeared that the hydrated cement also detached from the epoxy matrix; however, the particles seemed to become dispersed.

For the fly ash-filled epoxy (see Fig. 7d), most of the particles had been detached, indicated by many holes. Furthermore, the particles looked smoother compared to that in the dry condition. The smooth particles indicated that water might have been reacted with or hydrolyzed the component on the fly ash surface, creating a weak boundary layer and then leading to particles debonding. For the $\mathrm{CaCO}_{3}$-filled 

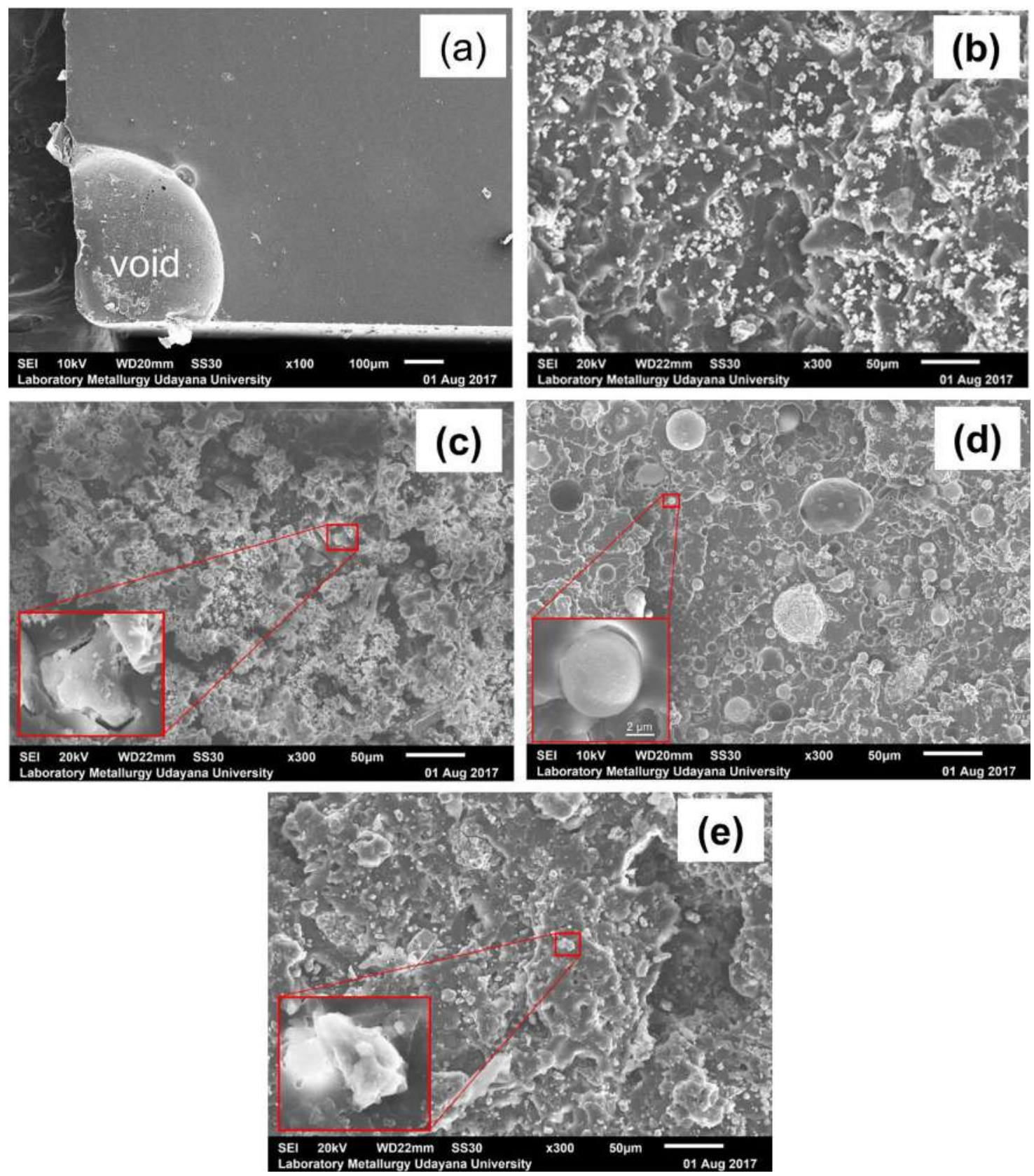

Fig. 7. SEM micrographs of (a) neat epoxy, (b) $5 \%$ and (c) $15 \%$ cement-, (d) $15 \%$ fly ash-, (e) $15 \% \mathrm{CaCO}_{3}$-filled epoxies in wet condition.

epoxy (Fig. 7e), $\mathrm{CaCO}_{3}$ did not chemically interact with water during aging, and the fracture surfaces seemed similar to that in the dry condition, where the $\mathrm{CaCO}_{3}$ particles debonded but more massive, indicated by many tiny holes. The debonded particles indicated that the $\mathrm{CaCO}_{3}$ particles had a weak interaction with epoxy. The massive debonded particles further confirmed the FTIR results (see the Supplementary material).

\section{Conclusions}

Investigation of the effect of filler volume fraction (Portland cement, fly ash, and $\mathrm{CaCO}_{3}$ ) on the water absorption-desorption behavior and the tensile properties of epoxy has been undertaken. It is worth noting that the order of water reactivity of the filler from the highest to the lowest is cement, fly ash and $\mathrm{CaCO}_{3}$. Some keys finding are summarized below: a The water uptake of epoxy filled with water-reactive filler (cement) increased with the increase of volume fraction, up to $128 \%$ at the volume fraction of $25 \%$. On the contrary, water uptake of epoxy filled with unreactive filler $\left(\mathrm{CaCO}_{3}\right)$ decreased with the increase of volume fraction, up to $41 \%$ at the volume fraction of $25 \%$.

b The water-reactive filler changed the water uptake behavior of neat epoxy from a pseudo Fickian to a non-Fickian and was well described using a Carter and Kibler diffusion law. Meanwhile, the unreactive filler did not affect the water uptake behavior of neat epoxy.

c The CME of epoxy filled with the less water-reactive filler (fly ash and $\mathrm{CaCO}_{3}$ ) tended to increase with the increase of volume fraction; however, for the epoxy filled with the reactive filler (cement), the effect of volume fraction on the CME became significant only when the volume fraction was beyond $15 \%$. The order of the CME from the highest to the lowest are $\mathrm{CaCO}_{3}$, fly ash-, and cement-filled epoxies, particularly at the high-volume fraction (beyond $15 \%$ ). 
d For all the studied fillers, in dry condition, the tensile modulus tended to increase with the increase of volume fraction; whereas, the tensile strength tended to decrease with the increase of volume fraction. The increase and decrease of elastic modulus and tensile strength, respectively with the increase of volume fraction, indicated that the elastic modulus seemed not sensitive to the interfacial strength of filler-matrix, but the tensile strength did. In wet condition, the positive effect of filler on the elastic modulus diminished with the increased volume fraction, which might be caused by plastic deformation due to the plasticization effect of water. However, the water-reactive filler, in this case, Portland cement had the lowest reduction.

e Halpin-Tsai's and Pukanszky et al.'s models respectively had been used to predict the elastic modulus and the tensile strength of the composite, as a function of filler volume fraction. In dry condition, Halpin-Tsai's and Pukanszky et al.'s models provided a good agreement with the experimental data. However, in wet condition, Halpin-Tsai's and Pukanszky et al.'s models could not well predict the elastic modulus and the strength, respectively, which could be attributed to the excessive matrix plastic deformation and very weak interfacial bonding.

\section{Data availability}

The raw/processed data required to reproduce these findings cannot be shared at this time as the data also forms part of an ongoing study.

\section{CRediT authorship contribution statement}

Sugiman Sugiman: Conceptualization, Methodology, Investigation, Writing -original draft. Salman Salman: Validation, Formal analysis, Visualization. Maryudi Maryudi: Writing - review \& editing.

\section{Declaration of Competing Interest}

The authors declare that they have no known competing financial interests or personal relationships that could have appeared to influence the work reported in this paper.

\section{Acknowledgements}

This work was supported by Ministry of Research, Technology and Higher Education, Republic of Indonesia under Fundamental Research scheme with grant number: 1836/UN18.L1/PP/2019.

\section{Appendix A. Supplementary data}

Supplementary material related to this article can be found, in the online version, at doi:https://doi.org/10.1016/j.mtcomm.2020. 101360.

\section{References}

[1] D. Ratna, Epoxy Composites: Impact Resistance and Flame Retardancy, Rapra Review Report, Report 185 Vol. 16 Smithers Rapra Press, Shrewsbury, United Kingdom, 2005 No. 6.

[2] P. Ghassemi, V. Toufigh, Durability of epoxy polymer and ordinary cement concrete in aggressive environments, Constr. Build. Mater. 234 (2020) 117887, , https://doi. org/10.1016/j.conbuildmat.2019.117887.

[3] J. Abraham, J. Thomas, A. Hafusa, S.C. George, S. Thomas, Chapter 11. Liquid transport through polymer nanocomposites, in: S. Thomas (Ed.), Transport Properties of Polymeric Membranes, Elsevier, 2018, , https://doi.org/10.1016/ B978-0-12-809884-4.00011-2.

[4] H. Alamri, I.M. Low, Effect of water absorption on the mechanical properties of nano-filler reinforced epoxy composites, Mater. Des. 42 (2012) 214-222, https:// doi.org/10.1016/j.matdes.2012.05.060.

[5] H. Alamri, I.M. Low, Effect of water absorption on the mechanical properties of nanoclay filled recycled cellulose fibre reinforced epoxy hybrid nanocomposites, Compos. Part A Appl. Sci. Manuf. 44 (2013) 23-31, https://doi.org/10.1016/j. compositesa.2012.08.026.

[6] W. Liu, S.V. Hoa, M. Pugh, Fracture toughness and water uptake of highperformance epoxy/nanoclay nanocomposites, Compos. Sci. Technol. 65 (2005) 2364-2373, https://doi.org/10.1016/j.compscitech.2005.06.007.

[7] Z. Ahmad, M.P. Ansell, D. Smedley, Effect of nano- and micro-particle additions on moisture absorption in thixotropic room temperature cure epoxy-based adhesives for bonded-in timber connections, Int. J. Adhes. Adhes. 30 (6) (2010) 448-455, https://doi.org/10.1016/j.ijadhadh.2010.04.001.

[8] M. Heshmati, R. Haghani, M. Al-Emrani, Effects of moisture on the long-term performance of adhesively bonded FRP/steel joints used in bridges, Compos. Part B Eng. 92 (2016) 447-462, https://doi.org/10.1016/j.compositesb.2016.02.021.

[9] S. Sugiman, P.D. Setyawan, S. Salman, H. Ahmad, Experimental and numerical investigation of the residual strength of steel-composites bonded joints: effect of media and aging condition, Compos. Part B Eng. 173 (2019) 106977, https://doi. org/10.1016/j.compositesb.2019.106977.

[10] H. Zhao, R.K.Y. Li, Effect of water absorption on the mechanical and dielectric properties of nano-alumina filled epoxy nanocomposites, Compos. Part A Appl. Sci. Manuf. 39 (2008) 602-611, https://doi.org/10.1016/j.compositesa.2007.07.006.

[11] M. Al-Qadhi, N. Merah, Z.M. Gasem, Mechanical properties and water uptake of epoxy-clay nanocomposites containing different clay loadings, J. Mater. Sci. 48 (2013) 3798-3804, https://doi.org/10.1007/s10853-013-7180-5.

[12] O. Starkova, S. Chandrasekaran, L.A.S.A. Prado, F. Tölle, R. Mülhaupt, K. Schulte, Hydrothermally resistant thermally reduced graphene oxide and multi-wall carbon nanotube based epoxy nanocomposites, Polym. Degrad. Stab. 98 (2013) 519-526, https://doi.org/10.1016/j.polymdegradstab.2012.12.005.

[13] G. Capiel, J. Uicich, V. Alvarez, P. Montemartini, Improving the water resistance of epoxy-anhydride matrices by the incorporation of bentonite, Polym. Adv. Technol. 28 (7) (2017) 886-896, https://doi.org/10.1002/pat.3993.

[14] A. Chateauminois, L. Vincent, B. Chabert, J.P. Soulier, Study of the interfacial degradation of a glass-epoxy composite during hygrothermal ageing using water diffusion measurements and dynamic mechanical thermal analysis, Polymer 35 (22) (1994) 4766-4774, https://doi.org/10.1016/0032-3861(94)90730-7.

[15] E. Nicaise, A. Gandini, H. Cheradame, Behavior of composites used in the confinement of nuclear wastes 2 - Water absorption in particle-filled epoxide networks, Brit. Polym. J. 18 (4) (1986) 251-255, https://doi.org/10.1002/pi.4980180410.

[16] O. Starkova, S. Chandrasekaran, T. Schnoor, J. Sevcenko, K. Schulte, Anomalous water diffusion in epoxy/carbon nanoparticle composites, Polym. Degrad. Stab. 164 (2019) 127-135, https://doi.org/10.1016/j.polymdegradstab.2019.04.010.

[17] H.G. Carter, K.G. Kibler, Langmuir type model for anomalous moisture diffusion in composite resins, J. Compos. Mater. 12 (1978) 118-131, https://doi.org/10.1177/ 002199837801200201.

[18] W.K. Loh, A.D. Crocombe, M.M.A. Wahab, I.A. Ashcroft, Modeling anomalous moisture uptake, swelling and thermal characteristics of a rubber toughened epoxy adhesive, Int. J. Adhes. Adhes. 25 (1) (2005) 1-12, https://doi.org/10.1016/j. ijadhadh.2004.02.002.

[19] M.D. Placette, X. Fan, J.-H. Zhao, D. Edwards, Dual stage modeling of moisture absorption and desorption in epoxy mold compounds, Microelectron. Reliab. 52 (2012) 1401-1408, https://doi.org/10.1016/j.microrel.2012.03.008.

[20] A. Ameli, N.V. Datla, M. Papini, J.K. Spelt, Hygrothermal properties of highly toughened epoxy adhesives, J. Adhes. 86 (2010) 698-725, https://doi.org/10. 1080/00218464.2010.482405.

[21] W. Liu, S.V. Hoa, M. Pugh, Water uptake of epoxy-clay nanocomposites: model development, Compos. Sci. Technol. 67 (2007) 3308-3315, https://doi.org/10. 1016/j.compscitech.2007.03.041.

[22] P. Gilormini, J. Verdu, On the role of hydrogen bonding on water absorption in polymers, Polymer 142 (2018) 164-169, https://doi.org/10.1016/j.polymer.2018. 03.033.

[23] H. He, J. Yang, W. Huang, M. Cheng, Influence of nano-calcium carbonate particles on the moisture absorption and mechanical properties of epoxy nanocomposite, Adv. Polym. Technol. 37 (4) (2016) 21751, https://doi.org/10.1002/adv.21751.

[24] P. Dittanet, R.A. Pearson, P. Kongkachuichay, Thermo-mechanical behaviors and moisture absorption of silica nanoparticle reinforcement in epoxy resins, Int. J. Adhes. Adhes. 78 (2017) 74-82, https://doi.org/10.1016/j.ijadhadh.2017.06.006.

[25] H. Khoramishad, O. Alizadeh, Effects of silicon carbide nanoparticles and multiwalled carbon nanotubes on water uptake and resultant mechanical properties degradation of polymer nanocomposites immersed in hot water, Polym. Compos. 39 (2017) E883-E890, https://doi.org/10.1002/pc.24303.

[26] S. Sugiman, S. Salman, Hygrothermal effects on tensile and fracture properties of epoxy filled with inorganic fillers having different reactivity to water, J. Adhes. Sci. Technol. 33 (7) (2019) 691-714, https://doi.org/10.1080/01694243.2018. 1558492.

[27] R.R. Irawan, Assesment of chemical, physical, and mechanical properties of Indonesian Portland cements, Jurnal Jalan-Jembatan 34 (2017) 79-90.

[28] Sugiman, P.D. Setyawan, Surface treatment of fly ash for improving the tensile strength of fly ash/unsaturated polyester composites, Makara Seri Teknologi 17 (3) (2013) 128-132, https://doi.org/10.7454/mst.v17i3.2932.

[29] ASTM D638-02a, Standard Test Method for Tensile Properties of Plastics, ASTM International, Pennsylvania, 2003.

[30] S.M. Ali, Ultrasonic and Thermo kinetic Characterization of Curing Epoxy Resin, Ph.D Thesis University of Nottingham, UK, 2013.

[31] P. Rosso, L. Ye, Epoxy/silica nanocomposites: nanoparticle-induced cure kinetics and microstructure, Macromol. Rapid Commun. 28 (2007) 121-126, https://doi org/10.1002/marc. 200600588.

[32] M. Ghaffari, M. Ehsani, H.A. Khonakdar, G.V. Assche, H. Terryn, The kinetic analysis of isothermal curing reaction of an epoxy resin-glassflake nanocomposite, Thermochim. Acta 549 (2012) 81-86, https://doi.org/10.1016/j.tca.2012.09.021. 
[33] B. De Neve, M.E.R. Shanahan, Water absorption by an epoxy resin and its effect on the mechanical properties and infra-red spectra, Polymer 34 (24) (1993) 5099-5105, https://doi.org/10.1016/0032-3861(93)90254-8.

[34] J. Crank, The Mathematic of Diffusion, 2nd edition, Oxford University Press, London, 1975

[35] M. Bouasker, P. Mounanga, P. Turcry, A. Loukili, A. Khelidj, Chemical shrinkage of cement pastes and mortars at very early age: effect of limestone filler and granular inclusions, Cem. Concr. Compos. 30 (1) (2008) 13-22, https://doi.org/10.1016/j. cemconcomp.2007.06.004.

[36] W.S. Chow, A. Abu Bakar, Z.A. Mohd Ishak, Water absorption and hygrothermal aging study on organomontmorillonite reinforced polyamide 6/polypropylene nanocomposites, J. Appl. Polym. Sci. 98 (2005) 780-790, https://doi.org/10.1002/ app. 22172 .

[37] W.S. Chow, Water absorption of epoxy/glass fiber/organo-montmorillonite nanocomposites, eXPRESS Polym, Lett. 1 (2) (2007) 104-108, https://doi.org/10.3144/ expresspolymlett.2007.18.

[38] G. Capiel, J. Uicich, D. Fasce, P.E. Montemartini, Diffusion and hydrolysis effects during water aging on an epoxy anhydride system, Polym. Degrad. Stab. 153 (2018) 165-171, https://doi.org/10.1016/j.polymdegradstab.2018.04.030.

[39] A. Lekatou, S.E. Faidi, D. Ghidaoui, S.B. Lyon, R.C. Newman, Effect of water and its activity on transport properties of glass/epoxy particulate composites, Compos. Part A Appl. Sci. Manuf. 28A (1997) 223-236, https://doi.org/10.1016/S1359-835X (96)00113-3.

[40] S.V. Mattigod, D. Rai, L.E. Eary, C.C. Ainswor, Geochemical factors controlling the mobilization of inorganic constituents from fossil fuel combustion residues: I. Review of the major elements, J. Environ. Qual. 19 (1990) 188-201, https://doi. org/10.2134/jeq1990.00472425001900020004x.

[41] R. Iyer, The surface chemistry of leaching coal fly ash, J. Hazard. Mater. B93 (2002) 321-329, https://doi.org/10.1016/S0304-3894(02)00049-3.

[42] B. Chen, B.-J. Ni, W.-T. Liu, Q.-Y. Ye, S.-Y. Liu, H.-X. Zhang, K.-B. Yoon, Mechanical properties of epoxy nanocomposites filled with melamine functionalized molybdenum disulfide, RSC Adv. 8 (2018) 20450-20455, https://doi.org/10.1039/ C8RA02689K.

[43] C. Wang, C. Piao, X. Zhai, F.N. Hickman, J. Li, Synthesis and characterization of hydrophobic calcium carbonate particles via a dodecanoic acid inducing process, Powder Technol. 198 (2010) 131-134, https://doi.org/10.1016/j.powtec.2009.10. 026.

[44] S. Popineau, C.R.- Mouro, C.S. Gaillet, M.E.R. Shanahan, Free/bound water absorption in an epoxy adhesive, Polymer 46 (2005) 10733-10740, https://doi.org/ 10.1016/j.polymer.2005.09.008.

[45] M.J. Adamson, Thermal-expansion and swelling of cured epoxy-resin used in graphite-epoxy composite materials, J. Mater. Sci. 15 (1980) 1736-1745, https://doi. org/10.1007/BF00550593.

[46] G.Z. Xiao, M.E.R. Shanahan, Swelling of DGEBA/DDA epoxy resin during hygrothermal aging, Polymer 39 (14) (1998) 3253-3260, https://doi.org/10.1016/ S0032-3861(97)10060-X.

[47] Y. Li, J. Miranda, H.-J. Sue, Moisture diffusion behavior in bismaleimide resin subjected to hygrothermal cycling, Polym. Eng. Sci. 42 (2) (2002) 375-381, https:// doi.org/10.1002/pen.10955.

[48] R.S. Cates, Influence of Crosslink Density on Swelling and Conformation of Surfaceconstrained Poly(N-isopropylacrylamide) Hydrogels, Graduate Theses and Dissertations University of South Florida, 2010, https://scholarcommons.usf.edu/ etd/1592/.

[49] Y. Yan, V. Sencadas, T. Jin, X. Huang, W. Lie, D. Wei, Z. Jiang, Effect of multiwalled carbon nanotubes on the crosslinking density of the poly(glycerol sebacate) elastomeric nanocomposites, J. Colloid Interface Sci. 521 (2018) 24-32, https:// doi.org/10.1016/j.jcis.2018.03.015.

[50] C.-H. Lee, J.-J. Park, The properties of DSC and DMA for epoxy nano-and micro mixture composites, Trans. Electr. Electron. Mater. 11 (2) (2010) 69-72, https:// doi.org/10.4313/TEEM.2010.11.2.069.

[51] L. Wang, Y. Tan, H. Wang, L. Gao, C. Xiao, Investigation on fracture behavior and mechanisms of DGEBF toughened by CTBN, Chem. Phys. Lett. 699 (2018) 14-21, https://doi.org/10.1016/j.cplett.2018.03.037.

[52] P. Pittayavinai, S. Thanawan, T. Amornsakchai, Manipulation of mechanical properties of short pineapple leaf fiber reinforced natural rubber composites through variations in crosslink density and carbon black loading, Polym. Test. 54 (2016) 84-89, https://doi.org/10.1016/j.polymertesting.2016.07.002.

[53] S.-Y. Fu, X.-Q. Feng, B. Lauke, Y.-W. Mai, Effects of particle size, particle/matrix interface adhesion and particle loading on mechanical properties of particulatepolymer composites, Compos. Part B Eng. 39 (2008) 933-961, https://doi.org/10. 1016/j.compositesb.2008.01.002.

[54] S. Lavinia, F. Benboudjema, J.M. Torrenti, B. Bissonnette, Prediction of elastic properties of cement pastes at early ages, Comput. Mater. Sci. 47 (3) (2010) 775-784, https://doi.org/10.1016/j.commatsci.2009.11.003.

[55] G. Wypych, Handbook of Fillers, 3rd ed., ChemTec Publishing, Ontario, 2010.

[56] T. Matsunaga, J.K. Kim, S. Hardcastle, P.K. Rohatgi, Crystallinity and selected properties of fly ash particles, Mater. Sci. Eng. A 325 (1-2) (2002) 333-343, https:// doi.org/10.1016/S0921-5093(01)01466-6.

[57] K. Wang, J. Wu, L. Ye, H. Zeng, Mechanical properties and toughening mechanisms of polypropylene/barium sulfate composites, Compos. Part A Appl. Sci. Manuf. 34 (2003) 1199-1205, https://doi.org/10.1016/j.compositesa.2003.07.004.

[58] V. Kushvaha, H. Tippur, Effect of filler shape, volume fraction and loading rate on dynamic fracture behavior of glass-filled epoxy, Compos. Part B Eng. 64 (2014) 126-137, https://doi.org/10.1016/j.compositesb.2014.04.016.

[59] U. Dharmalingam, M. Dhanasekaran, K. Balasubramanian, R. Kandasamy, Surface treated fly ash filled modified epoxy composites, Polmeros 25 (6) (2015) 540-546, https://doi.org/10.1590/0104-1428.2152.

[60] B. Pukanszky, G. Voros, Mechanism of interfacial interactions in particulate filled composites, Compos. Interfaces 1 (1993) 411-427, https://doi.org/10.1163/ 156855493 X00266.

[61] H. Wang, Y. Bai, S. Liu, J. Wu, C.P. Wong, Combined effects of silica filler and its interface in epoxy resin, Acta Mater. 50 (2002) 4369-4377, https://doi.org/10. 1016/S1359-6454(02)00275-6.

[62] J. Spanoudakis, R.J. Young, Crack propagation in a glass particle-filled epoxy resin: part 2 Effect of particle-matrix adhesion, J. Mater. Sci. 19 (1984) 487-496, https:// doi.org/10.1007/BF00553572.

[63] J.C. Halpin, Stiffness and expansion estimates for oriented short fiber composites, J. Compos. Mater. 3 (1969) 732-734, https://doi.org/10.1177/ 002199836900300419.

[64] J.C. Halpin, S.W. Tsai, Effects of Environmental Factors on Composite Materials, Technical Report, AFML-TR 67-423, 1969.

[65] T. Mori, K. Tanaka, Average stress in matrix and average energy of materials with misfitting inclusions, Acta Metall. 21 (1973) 571-574, https://doi.org/10.1016/ 0001-6160(73)90064-3.

[66] B.B. Johnsen, A.J. Kinloch, R.D. Mohammed, A.C. Taylor, S. Sprenger, Toughening mechanisms of nanoparticle-modified epoxy polymers, Polymer 48 (2007) 530-541, https://doi.org/10.1016/j.polymer.2006.11.038.

[67] T.H. Hsieh, A.J. Kinloch, K. Masania, A.C. Taylor, S. Sprenger, The mechanisms and mechanics of the toughening of epoxy polymers modified with silica nanoparticles, Polymer 51 (2010) 6284-6294, https://doi.org/10.1016/j.polymer.2010.10.048.

[68] D. Carolan, A.J. Kinloch, A. Ivankovic, S. Sprenger, A.C. Taylor, Mechanical and fracture performance of carbon fibre reinforced composites with nanoparticle modified matrices, Procedia Struct. Integr. 2 (2016) 096-103, https://doi.org/10. 1016/j.prostr.2016.06.013.

[69] B. Pukanszky, B. Turcsanyi, F. Tudôs, Effect of interfacial interaction on the tensile yield stress of polymer composites, in: H. Ishida (Ed.), Interfaces in Polymer, Ceramic, and Metal Matrix Composites, Elsevier, New York, 1988, p. 467.

[70] A.J. Kinloch, S.J. Shaw, D.A. Tod, D.L. Hunston, Deformation and fracture behavior of a rubber toughened epoxy: 1, Microstructure and fracture studies, Polymer 24 (1983) 1341-1354, https://doi.org/10.1016/0032-3861(83)90070-8.

[71] E.S. Greenhalgh, Failure Analysis and Fractography of Polymer Composites, Woodhead Publishing Limited and CRC Press LLC, Cambridge, 2009. 